\title{
THE EXPERIENCES OF ORAL CANCER PATIENTS: A NARRATIVE REVIEW
}

\author{
Maria Ishaq Khattak ${ }^{1,5}$, Muslim Khan ${ }^{2}$, Saad Ishaq Khattak ${ }^{3}$, Zohaib Khan ${ }^{4}$, Zia UI Haq ${ }^{5,6}$ and Norkhafizah \\ Saddki ${ }^{1 *}$ \\ ${ }^{1}$ School of Dental Sciences, Universiti Sains Malaysia, Health Campus, Kubang Kerian, Kota Bharu, Kelantan, \\ Malaysia \\ ${ }^{2}$ Department of Oral \& Maxillofacial Surgery, Khyber College of Dentistry, Peshawar, Pakistan \\ ${ }^{3}$ Sardar Begum Dental College, Ghandara University, Peshawar, Pakistan \\ ${ }^{4}$ Office of Research Innovation \& Commercialization, Khyber Medical University, Peshawar, Pakistan \\ ${ }^{5}$ Institute of Public Health \& Social Sciences, Khyber Medical University, Peshawar, Pakistan \\ ${ }^{6}$ Institute of Health and Wellbeing, University of Glasgow, Glasgow, United Kingdom
}

Corresponding author: Norkhafizah Saddki

Email: fizah@usm.my

\section{ABSTRACT}

This is a critical review of the current evidence on patients' experiences with oral cancer. The impact on the quality of life and implications to clinical practice and research were also discussed. A comprehensive search of three databases, PubMed, Scopus, and Google Scholar was undertaken. The search was restricted to English-language primary research papers from 2009 till 2019. The following keywords were used: mouth neoplasms, patients, experiences, oral cancer, physical, social, psychological. A total of 173 studies were retrieved using the search strategy. After removing duplicate reports and scrutinising those based on title and abstract, 68 studies were shortlisted for full text review. Three major themes emerged from the literature: (1) physical experiences of oral cancer patients, (2) psychological experiences of oral cancer patients, and (3) social experiences of oral cancer patients. Experiences of oral cancer patients are complex and subjective, and phases of physical, psychological, and social experiences of oral cancer have not been explored in detail. However, there is evidence that experiences such as pain, facial alterations, body image disturbances, anxiety, depression, social avoidance, social support, and financial implications affect patients' quality of life. This review underlines the importance of further research to look into the type of support needed to address various experiences of oral cancer patients.

Keywords: Oral Cancer, Patients, Experiences, Physical, Psychological, Social

\section{INTRODUCTION}

Oral cancer refers to malignant neoplasms of the lips, oral cavity, salivary glands and oropharynx, which correspond to the codes $\mathrm{C} 00-\mathrm{C} 10$ of the $10^{\text {th }}$ revision of the International Statistical Classification of Diseases and Related Health Problems (ICD-10) ${ }^{1}$. In 2018, there were an estimated 354,864 new cases of lip and oral cavity cancers, 52,799 new cases of salivary gland cancers, and 92,887 new cases of oropharyngeal cancers worldwide, and more than 250,000 deaths ${ }^{2}$. The survival rate for oral cancer is at approximately $50 \%{ }^{3}$. This poor rate has remained essentially unchanged since the past three decades despite the advances in therapeutic interventions ${ }^{4}$. Being among the 10 most common cancers in the world, oral cancer is considered a major public health problem ${ }^{4}$.

Treatment options for oral cancer include surgical resection, radiotherapy and chemotherapy, which can be administered alone or used in combination depending on location and stage of the tumour, as well as patient's overall health and personal preferences $^{5,6}$. Although there have been continuous improvements in the treatment modalities of oral cancer, collateral damages to the head and neck structures remain as the unwanted consequences ${ }^{7}$. Debilitating side effects associated with cancer therapy encompass short term and long terms complications arising in various conditions and degrees of severity, depending on the individual and the type of treatment such as stomatitis, infection, bleeding, mucositis, pain, loss of function, and xerostomia ${ }^{7}$.

Apart from the physical suffering, oral cancer treatments and complications can cause significant psychological stress not only of the patients but also their families and caregivers ${ }^{8-11}$. Following diagnosis of oral cancer, patients may express emotional and physiological traumatic experiences primarily as the oral region is a prominent part of the body ${ }^{12}$. Additionally, studies have suggested that after getting treatment for oral cancer, patients may develop multifaceted social challenges that disturb their daily life style causing deviations in interpersonal communication, decrease in social activities and work related concerns ${ }^{13,14}$.

Assessment of patient quality of life has therefore become an integral outcome measure for oral cancer treatment ${ }^{15}$. The World Health Organization (WHO) define quality of life as "an individual's perception of their position in life in the context of the culture and value systems in which they live and in relation to their goals, expectations, standards 
and concerns"16. It is a complex multidimensional concept that measures the relationship of a person's physical health, psychological state, personal beliefs, and social relations to the environment. There is a vast literature reporting the quality of life of oral cancer patients utilising generic and disease-specific instruments to quantitatively assess patients' health status and the impact of therapeutic applications ${ }^{15}$. Additionally, there are numerous qualitative studies that explore the meaning and understandings of individual oral cancer patients' personal life experiences ${ }^{17,18}$.

This narrative literature review compiles available evidence of oral cancer patient experiences across the disease trajectory. This will help health care professionals and policy makers to better understand the experiences of oral cancer patients and facilitate the development of comprehensive patient-centred care and support for the patients.

\section{METHODS}

Three electronic databases (PubMed, Scopus, and Google Scholar) were searched using seven major keywords "mouth neoplasms", "patients", "experiences", "oral cancer", "physical”, "social”, and "psychological" in combination. The following restrictions were applied to the search: 1) papers published in English language from 2009 till 2019, and 2) primary research papers reporting oral cancer patients' experiences. The online search was also supplemented by manual search and examination of the references listed in the identified research papers.

All primary studies reporting experiences of being diagnosed and treated for oral cancer published in English from 2009 till 2019 were identified. Titles and abstracts of the studies were screened. Duplicated studies and studies that were not related to oral cancer were removed. Any disagreement was resolved by discussion to achieve a consensus among all authors. Studies fulfilling the aims of this review were included for full review and exported to the reference managing software Mendeley version 1.19.4.

\section{RESULTS}

The search strategy and initial screening of abstracts and titles yielded 173 studies. After removing duplicates $(n=3), 170$ were scrutinized according to the pre-determined criteria and 108 were shortlisted for full text review. Following discussion and review, 68 studies were included in the final list.

The studies included in this review reported experiences of oral cancer patients from different cultural backgrounds living in 23 countries around the world. Except for the Antarctica and Africa, the remaining world continents were well represented with studies from Asia (China, India, Japan, Pakistan, and Taiwan), North America (Canada and
United States of America), South America (Brazil), Europe (Bosnia, Denmark, France, Germany, Ireland, Italy, Netherlands, Norway, Portugal, Sweden, Switzerland, and United Kingdom) and Australia/Oceania (Australia).

Three major themes emerged from the literature: (1) the physical experiences of oral cancer patients, (2) the psychological experiences of oral cancer patients (3) the social experiences of oral cancer patients. The findings of this review are presented in the light of these interrelated experiences.

The physical experiences of oral cancer patients The intensity of the physical impact related to oral cancer, as reflected in quality-of-life measures, differs significantly depending on the site and size of tumour, disease progression and type of treatment ${ }^{19-22}$. Pain is a highly prevalent physical symptom experienced among oral cancer patients ${ }^{23}$. Oral cancer patients reported experiencing pain irrespective of the disease stage although the pain often increases as the tumour progresses ${ }^{24-27}$. The features of oral cancer pain are unique. Besides experiencing pain at the primary tumour site $e^{10}$, pain is also generated from the constant need for oral cavity anatomical area to be functioning during the activities of daily living, particularly speaking, eating, chewing and swallowing ${ }^{20,28,29}$. Pain will further reduce the function ability of the oral cavity ${ }^{19,26,30}$. Pain is therefore reported as the worst symptom by oral cancer patients, exacerbated by the functional requirements and mechanical stimulation $^{31}$.

Collateral damages to the head and neck structures such as mouth, teeth and salivary glands are frequently encountered as unwanted consequences following cancer therapy, particularly radiotherapy directed to the head and neck area and chemotherapy ${ }^{32-34}$. Oral complications of cancer and cancer therapy comprise of acute and chronic toxicities resulting in various oral symptoms and signs including pain, reduced saliva quality and quantity leading to feeling of dry mouth or xerostomia which can make it difficult for patients to eat and speak, neurosensory changes (taste alteration, taste loss), mucosal infection (candida, herpes etc.), acute exacerbation of dental caries, gum inflammation, and limited opening of the jaw (trismus) and tongue function ${ }^{31,35-37}$. Oral cancer and its treatments can also result in facial disfigurement. The degree of facial disfigurement vary from mild to severe depending upon the tumour site, disease progression, and treatment type $^{38}$. Facial disfigurement may result in speech impairment, swallowing and chewing problems, difficulty in controlling oral secretions, pain and discomfort of neck and maxillofacial areas, and physical weakness due to poor nutrition ${ }^{39-41}$.

Human faces are unique and contribute to individual identity ${ }^{42}$. The face is one of the most fundamental parts of the body for self-recognition, body image, communication and interpersonal 
relationships ${ }^{43}$. Despite considerable advances in treatment therapies, facial disfigurement resulting from the cancer itself or its treatments is usually very noticeable and oral cancer patients may encounter associated social stigmatisation ${ }^{26,38,44}$. Facial disfigurement is also linked to experiences of anxiety and depression in both patients and caregivers $^{45,46}$. Most patients go through financial difficulties such that it is not feasible for them to go for facial reconstructive surgeries ${ }^{37,47}$.

\section{The psychological experiences of oral cancer patients}

The impacts of oral cancer are beyond functional limitations ${ }^{46,48}$. Oral cancer patients express the highest level of unmet needs in psychological domain $^{49}$. A cancer diagnosis can disrupt the life of almost any individual by threatening one's general sense of security and orderliness in life $\mathrm{e}^{50}$. Patients with oral cancer are prone to psychological distress that can happen immediately following diagnosis and during the treatment phase ${ }^{51}$. Psychological experiences related to oral cancer include depression, anxiety, stigma, distress, helplessness, and fear ${ }^{52-55}$. These psychological experiences were found to be related to disease progression, type of treatment and disease outcomes including body image disturbance ${ }^{52-55}$.

Body image disturbance is the perception of changes in body appearance including facial disfigurements, body function, or both ${ }^{40,56}$. The relationship between body image disturbance and experiences of distress and anxiety is complex and multifaceted $^{57}$. Personal dissatisfaction, feelings of unattractiveness and concerns about changes in body appearance often lead to social avoidance ${ }^{56,58}$. Additionally, patients may experience emotional and existential vulnerability arising from their feelings of being trapped in their body image ${ }^{50}$. The severity of psychological experiences is influenced by the patient's pre-operative state of mind, social environment, coping strategies, and acceptance of illness ${ }^{56}$.

As oral cancer progresses and treatment starts, the psychological experiences are commonly attributed to physical complications of the disease ${ }^{46}$. These include impairments of the basic functions of the mouth such as chewing, swallowing and ability to speak which vary according to the course of disease (remission, recurrence, progression, and end of life) and phase of treatment ${ }^{19,26,30}$. Different types of oral cancer treatment would have resulted in different degree of functional impairments and subsequent psychological outcomes ${ }^{59}$. Patients treated with combined therapies, particularly involving radiotherapy and/or chemotherapy, were more likely to experience functional impairments than those who had surgical resection alone ${ }^{59}$. Reciprocally, patients who underwent surgery alone have been shown to report more positive psychological change than those who had combined treatment of surgery and radiotherapy ${ }^{60}$.
The rates of depression generally increase with the growing tumour or the treatment-related physical symptoms ${ }^{61}$. Evidence has also shown that the level of anxiety is highest at pre-operation period while depression is highest at post-operation period ${ }^{51}$. This is in accordance to the number of patients experiencing the psychological impact; the number of patients experiencing anxiety is highest before start of therapy while the number of patients experiencing depression is highest soon after therapy ${ }^{61}$.

Emotional distress can remain high even after one month post-therapy before improving slowly after three months ${ }^{24}$. Additionally, upon discharge, many patients feel worried or anxious that the cancer will come back after therapy ${ }^{29,62}$. The constant pattern of high level of uncertainty during and one month after treatment may hinder cancer survivor's adjustment to daily life ${ }^{27}$. After three years, some patients are still worried about reoccurrence although the magnitude of the apprehensions does not impact their quality of life ${ }^{63}$. Nevertheless, throughout the oral cancer trajectory, patients will commonly feel powerless, diminished and dependent, with damaged self-esteem and the need to struggle to build self-image ${ }^{64,65}$.

The social experiences of oral cancer patients Social avoidance, social isolation, social distress, lack of social support from family and friends, health care professionals and health care system, altered social interactions, financial constraints are among social experiences described by oral cancer patients ${ }^{22,66-70}$. These social experiences do not occur in a vacuum. The social experiences are influenced by various levels of circumstantial events or conditions that disrupt patients' socioecology balance including symptoms and complications of oral cancer and the therapy such as xerostomia, taste disturbances, dietary restrictions, dysphagia and pain, and fatigue ${ }^{71-74}$. Patients with altered sense of affiliation may report problems related to social interactions or intimacy with their partners ${ }^{75}$.

Financial issues are related to the social experiences of oral cancer patients. The costs of oral cancer treatment and follow-up care can put patients and their families under great financial strain. Besides the cost of treatment, patients may face extra expenses for treating and/or managing symptoms and side effects of treatment and for travelling to and from the hospital $11,20,26,69,73,76$. Worse still, a high proportion of oral cancer patients had to reduce their work capacity following diagnosis, and many were unable to return to work after therapy ${ }^{76}$. Reduction of work hours and work loss, which are associated with employment status before diagnosis, cancer-related symptoms, tumour stage, presence of comorbidity, and treatment modalities, may lead to social isolation, reduced self-esteem, and impaired quality of life for survivors $9,26,41,58,76-78$. 
In addition to negative social experiences, patients with oral cancer also reported positive experiences in relation to their diseases, such as resilience, spiritual beliefs, and stronger family relationships ${ }^{11,79}$. Social support from family members can help patients cope with the physical, emotional and social distress associated with the disease and deal with the stigma of the disease and the fear of recurrence ${ }^{65}$. Social support is also positively associated with enhanced health-related quality of life. On the other hand, patients who experience less social support would be at greater risk for psychological symptoms and psychosocial dysfunction ${ }^{55,80}$. Social support is linked to social inequality, and it is apparent in the case of late diagnosis which is more prevalent in patients who live alone and have low education level ${ }^{81}$.

\section{DISCUSSION}

A diagnosis of oral cancer can have a significant impact, not just on the patient, but on their spouse/partner, family, and broader social network. Patients with oral cancer experience tremendous physical, psychosocial, and social challenges. The experiences are unique to the individual as each patient will respond differently to the disease and its treatment. While disease interpretation, outcomes and experiences of patient may vary, the close interrelatedness amongst physical functionality, psychological suffering and social distress of oral cancer is unquestionable.

Pain is a significant factor influencing the daily living activities of oral cancer patients ${ }^{82}$. The unpleasant experience of intense pain can also have negative impact on the social-emotional wellbeing, and subsequent quality of life of patients ${ }^{19,26,30,82,83}$. Impaired speech due to pain may also lead to changes in work and restriction of interpersonal relationships ${ }^{84}$. Inability to accomplish essential activities of daily living and having to rely on others may lead to psychological impact as patients feel lessened or limited by the condition ${ }^{85}$. Nevertheless, guided support by specialists has been shown to be helpful in enhancing patients' quality of life through development of positive coping strategies to deal with pain ${ }^{41}$. Pain often co-exist with fatigue $^{10,23}$, which was reported as the predominant physical symptom related with overall care and supportive needs ${ }^{29}$. The literature also suggests that patients with psychological support may have decreased intensity of physical experiences ${ }^{86}$.

Oral cancer and its therapy may result in permanent facial disfigurement that can cause not only oral dysfunctions, but is also associated with body image disturbances, anxiety and depression ${ }^{87}$. Patient often have concerns regarding their appearance and need to learn to cope with the way people react when looking at their face ${ }^{42,88}$. Patients may also encounter social stigmatisation associated with the facial disfigurement ${ }^{38}$. Quality of health care received and the attitude of health care professionals have significant influence on patient's narration of pain and the ability to self-govern life and cope with facial deformities ${ }^{89}$.

The decline in oral functionality changes the social functioning atmosphere of patients which is linked to the psychological consequences such as depression and emotional imbalance ${ }^{88}$. The state of anxiety and depression of oral cancer patients appears to reflect the general experience of anguish which relates to the state of psychological vulnerabilities at different disease stages and treatment phases. The issues of anxiety and depression found in oral cancer in this review is complex. The struggle arises as the relationship between depression, anxiety, functionality and quality of life is ill-defined ${ }^{88}$. Depression and anxiety are reported to have significant implications on the quality of life of oral cancer patients, influencing their thoughts about confronting mortality and dealing with morbidity ${ }^{90}$. Depression has marked effects on oral cancer patients because depressed patients are less likely to adhere to the recommended treatment; instead they are more likely to have extended hospital admissions and decreased ability for gaining normality after treatment ${ }^{91}$.

Disruptions in physiological functioning following oral cancer treatment may lead to social avoidance ${ }^{92,93}$. Additionally, loss of employment may place greater financial burden on the patients which will further reduce their psychological and social functioning ${ }^{94}$. Issues with employment are significantly associated with poor quality of life among patients as reflected by high levels of anxiety and social avoidance ${ }^{95}$. Clearly, there is a need for health care providers to comprehend and explore the expressions of depression, anxiety and building self-management skills in oral cancer patients in order to provide better quality of life ${ }^{96,97}$.

The support needed by oral cancer patients vary across the disease trajectory ${ }^{98}$. Some patients reported a fulfilling life with satisfaction, despite considerable degree of physical disability as a result of treatment ${ }^{99}$. Health care professionals should therefore pay careful attention to patient's perceptions of quality care and the specific needs of each patient ${ }^{100}$. However, it was reported that most oral cancer patients were dissatisfied with the way health care providers are helping them to cope with body changes, indicating unmet health needs among the patients ${ }^{39}$.

This narrative review identified physical, psychological, and social experiences of oral cancer patients. The review includes results from both quantitative and qualitative studies on heterogeneous samples of oral cancer patients from various cultural background using various quality of life instruments and interview topic guides respectively. However, the experiences presented in this review were derived, hence may not be the comprehensive narration of oral cancer experiences. Furthermore, none of the included studies reported 
physical, psychological, and social experience of oral cancer patients all at once.

Additionally, oral cancer is a broad term referring to malignant neoplasms of lip, oral cavity, salivary glands, and oropharynx. Indistinctness exists in the literature associated with the term used to describe the disease as some studies used the term 'head and neck cancer' to refer to malignant neoplasms of the oral and oropharynx area. Nevertheless, we have made the attempt to reduce this ambiguity by including studies that met the criteria for inclusion and studies on 'head and neck cancer' besides 'oral cancer'.

\section{CONCLUSION}

The experiences expressed by oral cancer patients are of varying nature with high subjectivity, reflective of the complexity of disease progression. This review delivers an overview of the physical, psychological, and social experiences of oral cancer patients across the disease trajectory that vary according to the affected site, stage of disease, type of therapy and other personal and environmental factors. The physical, psychological, and social stressors are often intertwined, both resulting from and contributing to each other. This review highlights the need for further qualitative research on the broad experiences of oral cancer patients that can help inform a better understanding of the issues.

A comprehensive list of experiences and a good understanding of patients' experiences would provide a sound basis for development of patientcentred and individualised care. Considering that oral cancer experiences are unique to each patient; this information would enable health care providers to focus on individual patient support requirements and needs depending on the patient's specific issues or challenges in life.

\section{REFERENCES}

1. World Health Organization. ICD-10: International Statistical Classification of Diseases and Related Health Problems 10th Revision. Geneva: World Health Organization 2011.

2. Bray F, Ferlay J, Soerjomataram I, et al. Global cancer statistics 2018: GLOBOCAN estimates of incidence and mortality worldwide for 36 cancers in 185 countries. CA Cancer J Clin 2018; 68(6):394-424.

3. Warnakulasuriya S. Global epidemiology of oral and oropharyngeal cancer. Oral Oncol 2009; 45(4-5):309-16.

4. Rivera C. Essentials of oral cancer. Int J Clin Exp Pathol 2015; 8(9):11884-94.

5. Chinn SB, Myers JN. Oral cavity carcinoma: Current management, controversies, and future directions. J Clin Oncol 2015; 33(29):3269-76.

6. Kerawala C, Roques T, Jeannon JP, et al. Oral cavity and lip cancer: United Kingdom National Multidisciplinary Guidelines. J Laryngol Otol 2016; 130(S2):S83-S9.

7. Wong HM. Oral complications and management strategies for patients undergoing cancer therapy. ScientificWorldJournal 2014; 2014:581795. doi: $10.1155 / 2014 /$.

8. Barber B, Dergousoff J, Nesbitt $M$, et al. Depression as a predictor of postoperative functional performance status (PFPS) and treatment adherence in head and neck cancer patients: a prospective study. $J$ Otolaryngol Head Neck Surg 2015; 44:38.

9. Chen SC, Tsai MC, Liu CL, et al. Support needs of patients with oral cancer and burden to their family caregivers. Cancer Nurs 2009; 32(6):473-81.

10. Rigoni L, Bruhn RF, De Cicco R, et al. Quality of life impairment in patients with head and neck cancer and their caregivers: a comparative study. Braz J Otorhinolaryngol 2016; 82(6):680-6.

11. Goswami S, Gupta SS. How cancer of oral cavity affects the family caregivers? - A cross-sectional study in Wardha, India, using the Caregiver Quality of Life Index Cancer questionnaire. South Asian J Cancer 2020; 9(1):62-5.

12. Zabora J, BrintzenhofeSzoc K, Curbow B, et al. The prevalence of psychological distress by cancer site. Psychooncology 2001; 10(1):19-28.

13. García-Peris P, Parón L, Velasco C, et al. Long-term prevalence of oropharyngeal dysphagia in head and neck cancer patients: Impact on quality of life. Clin Nutr 2007; 26(6):710-7.

14. Semple CJ, Dunwoody L, George Kernohan $W$, et al. Changes and challenges to patients' lifestyle patterns following treatment for head and neck cancer. $J A d v$ Nurs 2008; 63(1):85-93.

15. Chandu A, Smith AC, Rogers SN. Healthrelated quality of life in oral cancer: a review. J Oral Maxillofac Surg 2006; 64(3):495-502.

16. World Health Organization. WHOQOL: Measuring Quality Life. Geneva: World Health Organization 1997.

17. Griffiths MJ, Humphris GM, Skirrow PM, et 
al. A qualitative evaluation of patient experiences when diagnosed with oral cancer recurrence. Cancer Nurs 2008; 31(4):E11-7.

18. Scott SE, Grunfeld EA, Main J, et al. Patient delay in oral cancer: a qualitative study of patients' experiences. Psychooncology 2006; 15(6):474-85

19. Abbas S, Tariq MUU, Raheem A, et al. Assessment of factors affecting quality of life in oral squamous cell carcinoma patients using University of Washington Quality of Life Questionnaire. Cureus 2019; 11(1):e3904.

20. Cheng $\mathrm{CH}$, Wang $\mathrm{TJ}$, Lin YP, et al. The illness experience of middle-aged men with oral cancer. J Clin Nurs 2013; 22(23-24):3549-56.

21. Loorents V, Rosell J, Willner HS, et al. Health-related quality of life up to 1 year after radiotherapy in patients with head and neck cancer (HNC). Springerplus 2016; 5(1):669. doi: 10.1186/s40064-016-2295-1.

22. Maciejewski O, Smeets R, Gerhards F, et al. Gender specific quality of life in patients with oral squamous cell carcinomas. Head Face Med 2010; 6(21).

23. Kanchan S, Pushpanjali K, Tejaswini BD. Challenges faced by patients undergoing radiotherapy for oral cancer: A qualitative study. Indian J Palliat Care 2019; 25(3):436-9.

24. Chen SC, Liao CT, Chang JTC. Orofacial pain and predictors in oral squamous cell carcinoma patients receiving treatment. Oral Oncol 2011; 47(2):131-5.

25. Viana TSA, de Barros Silva PG, Pereira KMA, et al. Prospective evaluation of quality of life in patients undergoing primary surgery for oral cancer: Preoperative and postoperative analysis. Asian Pac J Cancer Prev 2017; 18(8):2093-100.

26. Chen $\mathrm{YH}$, Liang WA, Hsu CY, et al. Functional outcomes and quality of life after a 6-month early intervention program for oral cancer survivors: a single-arm clinical trial. PeerJ 2018; 6:e4419.

27. Haisfield-Wolfe ME, MCGuire DB, Soeken K, et al. Prevalence and correlates of symptoms and uncertainty in illness among head and neck cancer patients receiving definitive radiation with or without chemotherapy. Support Care Cancer 2012; 20(8):1885-93.

28. de Melo NB, de Sousa VM, Bernardino IM, et al. Oral health related quality of life and determinant factors in patients with head and neck cancer. Med Oral Patol Oral Cir Bucal 2019; 24(3):e281-e9.

29. Chen SC. Life experiences of Taiwanese oral cancer patients during the postoperative period. Scand J Caring Sci 2012; 26(1):98103.

30. Rogers SN, Cleator AJ, Lowe D, et al. Identifying pain-related concerns in routine follow-up clinics following oral and oropharyngeal cancer. World J Clin Oncol 2012; 3(8):116-25.

31. Pateman KA, Ford PJ, Batstone MD, et al. Coping with an altered mouth and perceived supportive care needs following head and neck cancer treatment. Support Care Cancer 2015; 23(8):2365-73.

32. Astrup GL, Rustøen T, Hofsø $\mathrm{K}$, et al. Symptom burden and patient characteristics: Association with quality of life in patients with head and neck cancer undergoing radiotherapy. Head Neck 2017; 39(10):2114-26.

33. Macedo DR, Anjos ACY. Experience of radiotherapy in head and neck. $R G O, \operatorname{Rev}$ Gaúch Odontol 2019; 67:e20190026.

34. Patterson JM, McColl E, Wilson J, et al. Head and neck cancer patients' perceptions of swallowing following chemoradiotherapy. Support Care Cancer 2015; 23(12):3531-8.

35. Ganzer H, Rothpletz-Puglia P, Byham-Gray L, et al. The eating experience in long-term survivors of head and neck cancer: a mixedmethods study. Support Care Cancer 2015; 23(11):3257-68.

36. Osthus AA, Aarstad AKH, Olofsson J, et al. Head and neck specific Health Related Quality of Life scores predict subsequent survival in successfully treated head and neck cancer patients: a prospective cohort study. Oral Oncol 2011; 47(10):974-9.

37. Airoldi M, Garzaro M, Raimondo L, et al. Functional and psychological evaluation after flap reconstruction plus radiotherapy in oral cancer. Head Neck 2011; 33(4):45868.

38. Costa EF, Nogueira TE, de Souza Lima NC, et al. A qualitative study of the dimensions of patients' perceptions of facial disfigurement after head and neck cancer surgery. Spec Care Dentist 2014; 34(3):11421.

39. Fingeret $M C$, Yuan $Y$, Urbauer D, et al. The 
nature and extent of body image concerns among surgically treated patients with head and neck cancer. Psychooncology 2012; 21(8):836-44.

40. Fingeret MC, Hutcheson KA, Jensen $\mathrm{K}$, et al. Associations among speech, eating, and body image concerns for surgical patients with head and neck cancer. Head Neck 2013; 35(3):354-60.

41. Mayre-Chilton KM, Talwar BP, Goff LM. Different experiences and perspectives between head and neck cancer patients and their care-givers on their daily impact of a gastrostomy tube. J Hum Nutr Diet 2011; 24(5):449-59.

42. Röing $M$, Hirsch JM, Holmström I, et al. Making new meanings of being in the world after treatment for oral cancer. Qual Health Res 2009; 19(8):1076-86.

43. McQuestion M, Fitch M. Patients' experience of receiving radiation treatment for head and neck cancer: Before, during and after treatment. Can Oncol Nurs J 2016; 26(4):325-35.

44. Wan Leung S, Lee TF, Chien CY, et al. Health-related quality of life in 640 head and neck cancer survivors after radiotherapy using EORTC QLQ-C30 and QLQ-H\&N35 questionnaires. BMC Cancer 2011; 11:128. doi:10.1186/471-2407-11128.

45. Fingeret MC, Vidrine DJ, Reece GP, et al. Multidimensional analysis of body image concerns among newly diagnosed patients with oral cavity cancer. Head Neck 2010; 32(3):301-9.

46. Foxwell KR, Scott SE. Exploring the concerns and needs of patients with terminal head and neck cancer and their caregivers. Social Science \& Dentistry 2010; $1(2): 88-96$.

47. Pierre CS, Dassonville O, Chamorey E, et al. Long-term quality of life and its predictive factors after oncologic surgery and microvascular reconstruction in patients with oral or oropharyngeal cancer. Eur Arch Otorhinolaryngol 2014; 271(4):801-7.

48. Jager-Wittenaar H, Dijkstra PU, Vissink A, et al. Malnutrition and quality of life in patients treated for oral or oropharyngeal cancer. Head Neck 2011; 33(4):490-6.

49. Henry M, Habib L-A, Morrison M, et al. Head and neck cancer patients want us to support them psychologically in the posttreatment period: Survey results.
Palliat Support Care 2014; 12(6):481-93.

50. Björklund $M$, Sarvimäki A, Berg A. Living with head and neck cancer: a profile of captivity. Journal of Nursing and Healthcare of Chronic Illness 2010; 2(1):2231.

51. Koizumi A, Matsushima E, Mochizuki Y, et al. Changes in the psychological characteristics of oral cancer patients in the perioperative period: a quantitative evaluation. J Med Dent Sci 2013; 60(1):4153.

52. Aarstad AK, Beisland E, Aarstad HJ. Personality, choice of coping and $\mathrm{T}$ stage predict level of distress in head and neck cancer patients during follow-up. Eur Arch Otorhinolaryngol 2012; 269(9):2121-8.

53. Chen SC, Lai YH, Liao CT, et al. Supportive care needs in newly diagnosed oral cavity cancer patients receiving radiation therapy. Psychooncology 2013; 22(6):1220-8.

54. Elani HW, Allison PJ. Coping and psychological distress among head and neck cancer patients. Support Care Cancer 2011; 19(11):1735-41.

55. Lee MS, Nelson AM, Thompson LMA, et al. Supportive care needs of oral cancer survivors: Prevalence and correlates. Oral Oncol 2016; 53:85-90. doi: $10.1016 /$ j.oraloncology.

56. Ellis MA, Sterba KR, Day TA, et al. Body image disturbance in surgically treated head and neck cancer patients: A patientcentered approach. Otolaryngol Head Neck Surg 2019; $161(2): 278-87$.

57. Chen C, Cao J, Wang L, et al. Body image and its associated factors among Chinese head and neck cancer patients undergoing surgical treatment: a cross-sectional survey. Support Care Cancer 2020; 28(3):1233-9.

58. Tadakamadla J, Kumar S, Lalloo R, et al. Qualitative analysis of the impact of oral potentially malignant disorders on daily life activities. PLoS One 2017; 12(4):e0175531.

59. Jehn P, Stier R, Tavassol F, et al. Physical and psychological impairments associated with mucositis after oral cancer treatment and their impact on quality of life. Oncol Res Treat 2019; 42(6):342-9.

60. Harding S, Moss TP. The impact of treatment for head and neck cancer on positive psychological change within a year of completing treatment. Int $J$ Oral Maxillofac Surg 2018; 47(3):302-8. 
61. Neilson K, Pollard A, Boonzaier A, et al. A longitudinal study of distress (depression and anxiety) up to 18 months after radiotherapy for head and neck cancer. Psychooncology 2013; 22(8):1843-8.

62. Hu TW, Cooke M, McCarthy A. A qualitative study of the experience of oral cancer among Taiwanese men. Int J Nurs Pract 2009; 15(4):326-33.

63. Ghazali N, Cadwallader E, Lowe D, et al. Fear of recurrence among head and neck cancer survivors: longitudinal trends. Psychooncology 2013; 22(4):807-13.

64. Bhalla A, Anup N, pal Bhalla A, et al. Oral health related quality of life (OHRQOL) amongst head and neck cancer patients undergoing chemotherapy and radiotherapy at Sawi Mansingh Hospital Jaipur, India. Scholars Academic Journal of Biosciences 2015; 3(1A):3-12.

65. Deepan Kumar CV, Joseph J, Janakiram C, et al. Health-related quality of life and the perceived palliative care needs among oral cancer patients. J Indian Assoc Public Health Dent 2017; 15:327-33.

66. Baumann $E$, Scherer $H$, Link $E$, et al. Exploratory research focusing on oral cancer prevention: Challenges of dealing with informational and cognitive barriers. Qual Health Res 2019; 29(13):1930-41.

67. Losi E, Guberti $M$, Ghirotto $L$, et al. Undergoing head and neck cancer surgery: A grounded theory. Eur J Cancer Care (Engl) 2019; 28(4):e13062.

68. Manne S, Hudson SV, Baredes S, et al. Survivorship care experiences, information, and support needs of patients with oral and oropharyngeal cancer. Head Neck 2016; 38 (Suppl 1):E1935-46.

69. O'Brien KM, Timmons A, Butow $\mathrm{P}$, et al. Associations between neighbourhood support and financial burden with unmet needs of head and neck cancer survivors. Oral Oncol 2017; 65:57-64.

70. Silveira AP, Gonçalves J, Sequeira T, et al. Geriatric oncology: comparing health related quality of life in head and neck cancer patients. Head Neck Oncol 2011; 3:3. doi: 10.1186/758-3284-3-3.

71. Ehrsson YT, Sundberg K, Laurell G, et al. Head and neck cancer patients' perceptions of quality of life and how it is affected by the disease and enteral tube feeding during treatment. Ups J Med Sci 2015; 120(4):280-
9.

72. Fromm L, Gotfredsen K, Wessel I, et al. Oral health-related quality of life, oral aesthetics and oral function in head and neck cancer patients after oral rehabilitation. J Oral Rehabil 2019; 46(8):738-46.

73. Majid A, Sayeed BZ, Khan M, et al. Assessment and improvement of quality of life in patients undergoing treatment for head and neck cancer. Cureus 2017; 9(5):e1215.

74. Merrick S, Farrell D. Head and neck cancer patients' experiences of percutaneous endoscopic gastrostomy feeding: a Qmethodology study. Eur J Cancer Care (Engl) 2012; 21(4):493-504.

75. Low C, Fullarton M, Parkinson E, et al. Issues of intimacy and sexual dysfunction following major head and neck cancer treatment. Oral Oncol 2009; 45(10):898903.

76. Giuliani M, Papadakos J, Broadhurst M, et al. The prevalence and determinants of return to work in head and neck cancer survivors. Support Care Cancer 2019; 27(2):539-46.

77. Deno M, Tashiro M, Miyashita M, et al. The mediating effects of social support and selfefficacy on the relationship between social distress and emotional distress in head and neck cancer outpatients with facial disfigurement. Psychooncology 2012; $21(2): 144-52$.

78. Wells $M$, Swartzman $S$, Lang $H$, et al. Predictors of quality of life in head and neck cancer survivors up to 5 years after end of treatment: a cross-sectional survey. Support Care Cancer 2016; 24(6):2463-72.

79. Gao Y, Yuan L, Pan B, et al. Resilience and associated factors among Chinese patients diagnosed with oral cancer. BMC Cancer 2019; 19(1):447. doi: 10.1186/s12885-0195679-0.

80. Dzebo S, Mahmutovic J, Erkocevic $\mathrm{H}$. Quality of life of patients with oral cavity cancer. Mater Sociomed 2017; 29(1):30-4.

81. Kjaer TK, Johansen C, Andersen E, et al. Influence of social factors on patientreported late symptoms: Report from a controlled trial among long-term head and neck cancer survivors in Denmark. Head Neck 2016; 38(Suppl 1):E1713-21.

82. Schaller A, Dragioti E, Liedberg GM, et al. 
Quality of life during early radiotherapy in patients with head and neck cancer and pain. J Pain Res 2017; 10:1697-704.

83. Shavi GR, Thakur B, Bhambal A, et al. Oral health related quality of life in patients of head and neck cancer attending cancer hospital of Bhopal City, India. J Int Oral Health 2015; 7(8):21-7.

84. Cnossen IC, de Bree R, Rinkel RN, et al. Computerized monitoring of patientreported speech and swallowing problems in head and neck cancer patients in clinical practice. Support Care Cancer 2012; 20(11):2925-31.

85. Goswami S, Gupta SS, Raut A. Understanding the psychosocial impact of oral cancer on the family caregivers and their coping up mechanism: A qualitative study in Rural Wardha, Central India. Indian J Palliat Care 2019; 25(3):421-7.

86. Naughton MJ, Weaver KE. Physical and mental health among cancer survivors: considerations for long-term care and quality of life. N C Med J 2014; 75(4):2836.

87. Kim RH, Yang P, Sung EC. Managing intraoral lesions in oral cancer patients in a general dental practice: An overview. J Calif Dent Assoc 2016; 44(2):85-92.

88. Llewellyn CD, McGurk M, Weinman J. Are psycho-social and behavioural factors related to health related-quality of life in patients with head and neck cancer? A systematic review. Oral Oncol 2005; 41(5):440-54.

89. Cremonese G, Bryden G, Bottcher C. A multidisciplinary team approach to preservation of quality of life for patients following oral cancer surgery. ORL Head Neck Nurs 2000; 18(2):6-11.

90. Lydiatt WM, Moran J, Burke WJ. A review of depression in the head and neck cancer patient. Clin Adv Hematol Oncol 2009; 7(6):397-403.

91. Hassanein KA, Musgrove BT, Bradbury E. Functional status of patients with oral cancer and its relation to style of coping, social support and psychological status. $\mathrm{Br}$ J Oral Maxillofac Surg 2001; 39(5):340-5.

92. Chasen MR, Bhargava R. A descriptive review of the factors contributing to nutritional compromise in patients with head and neck cancer. Support Care Cancer 2009; 17(11):1345-51.

93. Duke RL, Campbell BH, Indresano AT, et al. Dental status and quality of life in longterm head and neck cancer survivors. Laryngoscope 2005; 115(4):678-83.

94. Verdonck-de Leeuw IM, van Bleek WJ, René Leemans $C$, et al. Employment and return to work in head and neck cancer survivors. Oral Oncol 2010; 46(1):56-60.

95. Rogers SN, Harvey-Woodworth CN, Hare J, et al. Patients' perception of the financial impact of head and neck cancer and the relationship to health related quality of life. Br J Oral Maxillofac Surg 2012; 50(5):4106.

96. Hassanein KA, Musgrove BT, Bradbury E. Psychological outcome of patients following treatment of oral cancer and its relation with functional status and coping mechanisms. J Craniomaxillofac Surg 2005; 33(6):404-9.

97. Hortense FTP, Bergerot CD, Domenico EBL. Quality of life, anxiety and depression in head and neck cancer patients: a randomized clinical trial. Rev Esc Enferm USP 2020; 54:e03546. doi: 10.1590/S1980$220 \times 2018040103546$.

98. Moore KA, Ford PJ, Farah CS. Support needs and quality of life in oral cancer: a systematic review. Int J Dent Hyg 2014; 12(1):36-47.

99. Llewellyn CD, Weinman J, McGurk M. A cross-sectional comparison study of cognitive and emotional well-being in oral cancer patients. Oral Oncol 2008; 44(2):124-32.

100. Moore KA, Ford PJ, Farah CS. "I have quality of life...but...": Exploring support needs important to quality of life in head and neck cancer. Eur J Oncol Nurs 2014; 18(2):192200. 